\title{
Role of trauma from occlusion in periodontal disease- A controversy
}

\author{
Dr. Rizwan M. Sanadi ${ }^{1}$, Dr. Laksha R. Chelani ${ }^{2}$, Dr. Susmita R. Bhakkand ${ }^{3}$, \\ Dr. Jimit K. Sheth ${ }^{4}$ \\ ${ }^{l}$ Professor, Department of Periodontics, Dr. G.D. Pol Foundation Y.M.T Dental College and Hospital, \\ Navi Mumbai. \\ ${ }^{2}$ PG student $3^{\text {rd }}$ year, Department of Periodontics, Dr. G.D. Pol Foundation Y.M.T Dental College and Hospital, \\ Navi Mumbai.

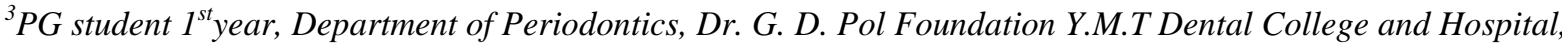 \\ Navi Mumbai. \\ ${ }^{4}$ PG student $3{ }^{\text {rd }}$ year, Department of Periodontics, Dr. G.D. Pol Foundation Y.M.T Dental College and \\ Hospital, Navi Mumbai.
}

\begin{abstract}
For more than a century, dental care professionals have debated whether or not trauma from occlusion is associated with periodontal disease. Both occlusal trauma and periodontitis result in injury to the attachment apparatus because the periodontium is unable to cope with the pathological insult which it experiences. Occlusal traumatism is nowadays generally accepted as a distinct pathologic entity unassociated with periodontitis, related tissue changes are regarded as microscopic, non-inflammatory and limited to attachment apparatus. The effects of excessive occlusal force and the destructive, adaptive and reparative response of the periodontium has been complicated by a relative lack of evidence based on well controlled prospective studies in human beings. A clinician's decision whether or not to use occlusal adjustment as a component of periodontal therapy should be related to an evaluation of clinical factors involving patient comfort and function, and not based on the assumption that occlusal adjustment is necessary to stop the progression of periodontitis. The present article discusses the role of trauma from occlusion in periodontal disease.
\end{abstract}

Keywords: attachment apparatus, occlusal adjustment, occlusal traumatism, pathologic entity, periodontal disease

\section{Introduction}

Mastication is the major function of the dentition and since the periodontium constitutes the supporting mechanism which enables the teeth to fulfil this function, consideration of the interrelation between occlusal forces and the periodontium is basic in periodontology. The etiology of periodontal disease is multifactorial. One of the factors, thought to be responsible for the initiation of inflammatory periodontal disease, is occlusal trauma ${ }^{[1]}$ Although a variety of occlusal conditions have reportedly been related to inflammatory periodontal disease (e.g. bruxism, malocclusion, abfraction etc.), the central focus has been on occlusal trauma (primary and secondary) resulting from excessive force(s) applied to the periodontium. ${ }^{[2]}$

This article attempts to address the clinical and histological effects of abnormal occlusal forces on the teeth and periodontium and to provide the diagnosis and treatment modalities for the same.

\section{Definition}

When the occlusal forces exceed the adaptive capacity of the tissues, tissue injury results. The resultant injury is termed trauma from occlusion (TFO). Thus, trauma from occlusion refers to the tissue injury, not the occlusal force. An occlusion that produces such injury is called a traumatic occlusion. ${ }^{[1]}$

It may manifest in the periodontium, hard structures of the teeth, pulp, temporomandibular joint, soft tissues of the mouth and neuromuscular system. However in periodontics, the term trauma from occlusion is usually applied to an occlusal periodontal relationship with evidence of traumatic periodontal injury.

\section{Etiology}

There are many factors involved in the etiology of TFO. They can be divided into two broad categories: precipitating factors and predisposing factors. ${ }^{[2]}$ In case of TFO, the precipitating factor is destructive occlusal forces. These forces when within normal range can be well adapted by the tooth supporting soft tissues. But when these forces exceed the adaptive capacity of tooth supporting tissues, pathologic changes can be seen 
in the soft tissues. These forces are normally described in terms of magnitude, direction, duration of application and frequency of application.

The predisposing factors are those which contribute to the development of TFO indirectly. The intrinsic factors include morphologic characteristics of the roots, alveolar process and the manner in which the occlusal surfaces and roots are oriented in relation to the forces to which they are exposed. The extrinsic factors that may seriously increase the rapidity of loss of supporting alveolar bone are: irritants such as microbial plaque, neuroses resulting in parafunctional activities, loss of supporting bone or teeth and iatrogenically created functional malocclusion.

I. Physiologic or Traumatic Occlusion ${ }^{[3]}$

\section{Classification of TFO}

II. Acute or Chronic (depending on the duration of cause) ${ }^{[2]}$

III. Primary or Secondary (depending on the nature of cause)

Physiologic occlusion is a condition in which the system of forces acting upon the tooth during occlusion, are in a state of equilibrium and they do not and cannot change the normal relationship existing between the tooth and its supporting structures. In this, the occlusal pressure against the tooth is balanced by the resistance of periodontal tissues.

Traumatic occlusion is where the damage produced in the periodontium is due to the overstress caused by the occlusion. Acute trauma results from an abrupt occlusal impact such as that produced by biting on a hard object. In addition, restorations or prosthetic appliances that interfere with or alter the direction of occlusal forces on the teeth may induce acute trauma.

Chronic trauma most often develops from gradual changes in occlusion produced by tooth wear, drifting movement and extrusion of teeth combined with parafunctional habits such as bruxism and clenching, rather than as a sequelae of acute periodontal trauma.

Primary TFO results from abnormal occlusal forces on relatively sound periodontal structure.

Secondary TFO results from physiologic or abnormal occlusal forces that act on a dentition that is seriously weakened by the loss of supporting alveolar bone.

\section{Historical studies}

The earliest studies considered traumatic occlusion as an etiologic factor for periodontal disease. The experimental studies and histopathologic studies of sections of human jaws at autopsy have proved that occlusal trauma is a definite cause of certain pathologic disturbances in the periodontal membrane. The observations in human autopsy which substantiated the presence of occlusal trauma included abrasion, cemental tears, root and alveolar bone resorption, periodontal membrane injuries and fractures of teeth.

In the 1960s, the role of microorganisms as the cause of periodontitis became more accepted. This led to a switch in theory in which traumatogenic occlusion was no longer considered as a causative agent but as a cofactor in the progression of periodontitis.

Although the studies in the 1960s had clearly demonstrated that occlusal forces transmitted to the periodontium could cause both physiologic and pathologic changes in the alveolar bone and PDL, they did not prove that these changes affected the progression of periodontal attachment loss. Researchers developed animal models to study the effects of traumatogenic occlusion on bone loss and periodontal attachment loss (Lindhe and Svanberg 1974, Meitner 1975, Nyman et al 1978, Ericcson and Lindhe 1982, Polson and Zander 1983). ${ }^{[4-7]}$ However, these do not duplicate the dynamics of the human masticatory function nor rule out significant differences between animal and man.

In the late 1980s, research on the effect of occlusion on periodontitis slowed considerably as researchers became more interested in projects concerning dental implants, periodontal regeneration and diagnostic techniques to identify progression of periodontitis. Human research studies reported from 1986-87 questioned the effects of occlusal forces on the progression of periodontitis (Hakkarainen 1986, Philstrom et al 1986, Houston et al 1987). ${ }^{[8-10]}$

\section{Tissue response to TFO}

The tissue injury occurs in three stages ${ }^{[11]}$, i.e. injury, repair and adaptive remodelling of the periodontium. Tissue injury is produced by excessive occlusal forces. Nature attempts to repair the injury and restore the periodontium. This can occur if the forces are diminished or if the tooth drifts away from them. When bone is resorbed by excessive occlusal forces, the body attempts to reinforce the thinned bony trabeculae with new bone. This attempt to compensate for the lost bone is called 'Buttressing Bone Formation.' When this occurs within the jaw, it is called 'Central Buttressing,' wherein the endosteal cells deposit the new bone, which 
restores the bony trabeculae and reduces the size of the marrow spaces. 'Peripheral Buttressing'occurs on the facial and lingual surfaces of the alveolar plate. Depending on the severity, peripheral buttressing may produce shelf like thickening of the alveolar margin, called as 'Lipping' or a pronounced bulge in the contour of the facial and lingual bone.

If the offending force is chronic, the periodontium is remodelled to cushion its impact. The ligament is widened at the expense of bone, angular bone defects occur without periodontal pockets and the tooth becomes loose.

Figure- 1

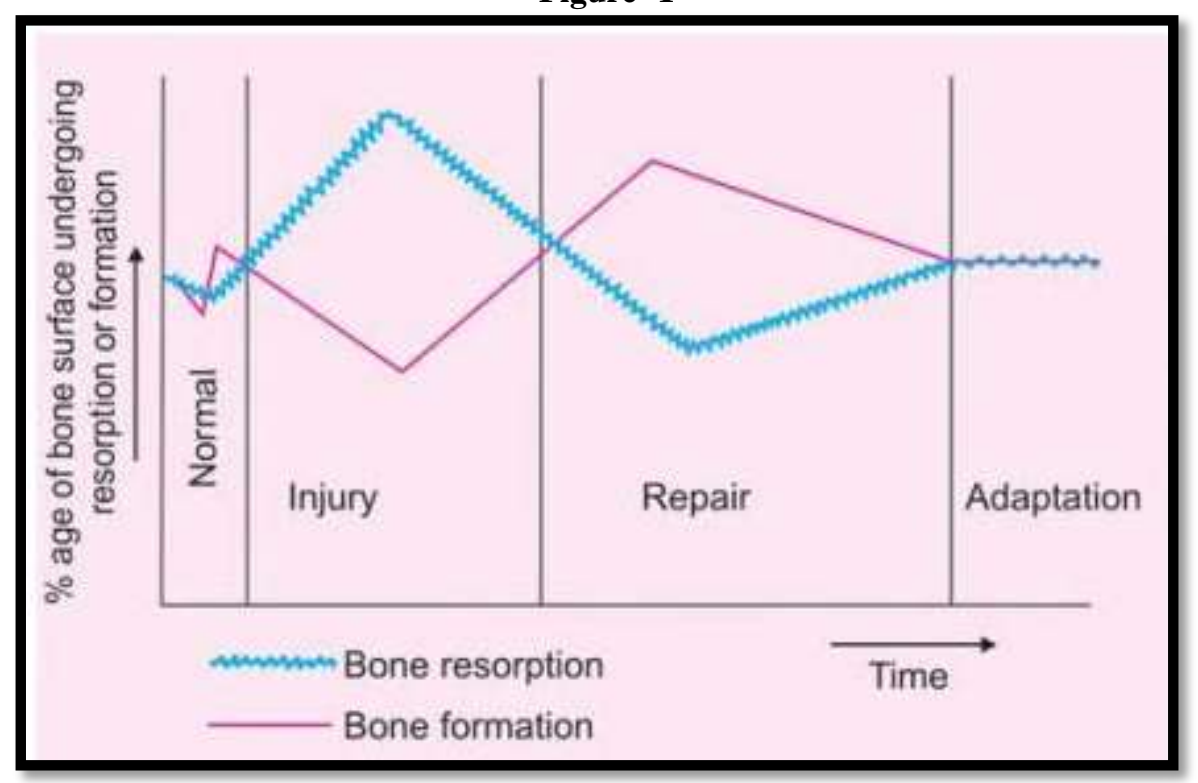

Stages of tissue response to increased occlusal forces

\section{Diagnosis of TFO}

The clinical history of the patient and clinical examination are the cornerstones of correct diagnosis of trauma from occlusion. The symptoms of TFO include periodontal pain, pulpal pain, food impaction, traumatic temporomandibular joint arthritis and muscle pain and loose teeth.

Table 1- Signs of TFO

\begin{tabular}{|l|l|}
\hline Clinical signs & Radiographic signs \\
\hline Mobility & Widening of the periodontal ligament(PDL) space \\
\hline $\begin{array}{l}\text { Positive fremitus } \\
\text { test }^{[12]}\end{array}$ & $\begin{array}{l}\text { Thickening of the lamina dura in the apical region and in bifurcation } \\
\text { areas }\end{array}$ \\
\hline $\begin{array}{l}\text { Occlusal } \\
\text { prematurities }^{[13]}\end{array}$ & $\begin{array}{l}\text { Vertical destruction of the interdental septum with formation of } \\
\text { infrabony defects }\end{array}$ \\
\hline Wear facets & Radiolucence and condensation of the alveolar bone \\
\hline Tooth migration & Root resorption \\
\hline Fractured teeth & \\
\hline Thermal sensitivity & \\
\hline
\end{tabular}

Occlusal trauma and tooth mobility are associated with periodontal bone and attachment loss. It follows that over many years, this association may lead to enough destruction of periodontal support to threaten periodontal longevity. ${ }^{[14]}$ As TFO is defined and diagnosed on the basis of histologic changes in the periodontal supporting structure, a diagnosis of TFO is impossible without block section biopsy. Because this is clearly impractical for the clinical practice of periodontics, the clinician must rely on the clinical signs of occlusal trauma.

\section{Treatment of TFO}

The treatment of TFO involves removal of the excessive occlusal forces and bringing the tooth/ teeth in comfortable position. Many treatment modalities have been advised to treat TFO. These include- 
8.1 Occlusal adjustment- is the establishment of functional relationships favourable to the periodontium by one or more of the following: coronoplasty, dental restorations, tooth movements, tooth removal, orthognathic surgery. ${ }^{[15]}$

8.2 Management of parafunctional habits- habits like bruxism cause excessive forces on the periodontium leading to its injury. The correct diagnosis of bruxism should be made by taking history of the patient and associated clinical findings. There are several short-term modalities by which the patient with bruxism can be treated- the behavioral modality, behavioral therapies such as electromyographic (EMG) biofeedback may be prescribed, ${ }^{[16,17]}$ a brief course of physical therapy, medications prescribed for a few days aimed at altering sleep arousal or anxiety level and the maxillary stabilization appliance which remains the most universal and effective long-term means of interfering with the effects of bruxism.

8.3 Temporary, provisional or long-term stabilisation of mobile teeth with removable or fixed appliancesA splint is an appliance for immobilization or stabilization of injured or diseased parts. ${ }^{[18]}$ In dentistry, splinting is joining together of two or more teeth to increase resistance to the applied force through stabilization. ${ }^{[19]}$ It could be for a short-term, provisional or long-term purpose.

8.4 Orthodontic tooth movement-A periodontally compromised tooth with little bone support is not a good candidate for orthodontic tooth movement. Moving the tooth in a position which will further compromise its stability and long term prognosis is also not desirable. Tooth movement which eliminates abnormal occlusal forces as well as improves its long term prognosis, should be the primary goal during application of orthodontic forces on the tooth.

8.5 Occlusal reconstruction- it is the redesigning of the complete occlusal scheme. It is done in cases where, by no other means occlusal equilibration can be achieved. It involves redesigning the occlusal contacts by giving crowns, bridges or implant-supported prosthesis.

8.6 Extraction of selected teeth- In certain situations extraction of selected tooth/teeth may be done, such as a tooth with extensive periodontal involvement, having a poor prognosis and extraction of teeth which may improve prognosis of the remaining teeth. During orthodontic treatment also, extraction of certain teeth may be indicated for proper final positioning and alignment.

\section{Conclusion}

Over the years, studies have strongly indicated that excessive occlusal forces are not a causal factor in the initiation of periodontal disease. Plaque is the primary causal factor in periodontal disease and it is believed its control should be a priority in any periodontal treatment. ${ }^{[20]}$ Occlusal forces may be a cofactor in the progression of periodontal disease. Treatment of occlusal discrepancies may be a beneficial adjunct to routine periodontal therapy. Plaque control and proper oral hygiene are the primary factors which focus on elimination of inflammation from the periodontal tissues. Elimination of the abnormal occlusal forces along with stabilization of the involved tooth/teeth is the primary treatment for trauma from occlusion.

\section{References}

[1]. Newman MG, Takei HH, Carranza FA. Carranza's Clinical Periodontology (9th ed. Missouri: Saunders; 2003 ). p.371.

[2]. Carranza F and Neumann. Clinical Periodontology(8th ed. WB Saunders Co; 1996). p.313-324.

[3]. Sorrin S.The practice of periodontia. (McGraw Hill Book Co; 1960). p. 224-298.

[4]. Polson AM. Interrelationship of inflammation and tooth mobility (trauma) in pathogenesis of periodontal disease. J Clin Periodontol 1980; 7(5):351-60.

[5]. Kantor M, Polson AM, Zander HA. Alveolar bone regeneration after removal of inflammatory and traumatic factors. J Periodontol 1976; 47(12):687-95.

[6]. Lindhe J, Ericsson I. The effect of elimination of jiggling forces on periodontally exposed teeth in the dog. J Periodontol 1982; 53(9):562-7.

[7]. Lindhe J, Ericsson I. The influence of trauma from occlusion on reduced but healthy periodontal tissues in dogs. J Clin Periodontol $1976 ; 3(2): 110-22$.

[8]. Hanamura H, Houston F, Rylander H, Carlsson GE, Haraldson T, Nyman S. Periodontal status and bruxism: A comparative study of patients with periodontal disease and occlusal parafunctions. J Periodontol 1987; 58(3):173-6.

[9]. Philstrom B, Anderson KA, Aeppli D. Association between signs of trauma from occlusion and periodontitis. J Periodontol 1986; 57:1-6.

[10]. Hakkarainen K. Relative influence of scaling and root planing and occlusal adjustment on sulcular fluid flow. J Periodontol1986; 57(11):681-4

[11]. Carranza FA Jr. Histometric evaluation of periodontal pathology. J Periodontol 1970; $38: 741$.

[12]. Genco RJ, Goldman HM, Cohen WD. Contemporary Periodontics. (The C.V. Mosby Company; 1990).

[13]. Glickmann I. Clinical Periodontology.(5th ed. WB Saunders Co).p.947-987.

[14]. Reinhardt R, Killeen AC. Do mobility and occlusal trauma impact periodontal longevity? Dent Clin N Am 2015; 59:873-883.

[15]. Serio FG, Hawley CE.Periodontal trauma and mobility: Diagnosis and treatment planning. Dent Clin North Am 1999; 43(1):37-44.

[16]. Pertes R, Vella M, Milone A. Vertical skeletal facial types and condylar position in TMJ patients. J Dent Res 1989; 68:195. 
[17]. Rugh JD, Solberg WK. Electromyographic evaluation of bruxist behaviour before and after treatment. Can Dent Assoc J 1975; 3:56.

[18]. McCall JO. Principles of periodontics.(3rd ed. J. B. Lippincott Co; 1964). p.15.

[19]. Wank GS, Kroll YJ. Occlusal trauma: An evaluation of its relationship to periodontal prostheses. Dent Clin North Am 1981; 25(3):511-32

[20]. Harell SK, Nunn ME, Hallmon WW. Is there an association between occlusion and periodontal destruction? J Am Dent Assoc 2006; 137:1380-92. 